\title{
Nanocellular Polymers with a Gradient Cellular Structure Based on Poly(methyl methacrylate)/Thermoplastic Polyurethane Blends Produced by Gas Dissolution Foaming
}

\author{
Victoria Bernardo, * Judith Martin-de Leon, Ismael Sanchez-Calderon, \\ Ester Laguna-Gutierrez, and Miguel Angel Rodriguez-Perez
}

Graded structures and nanocellular polymers are two examples of advanced cellular morphologies. In this work, a methodology to obtain low-density graded nanocellular polymers based on poly(methyl methacrylate) (PMMA)/ thermoplastic polyurethane (TPU) blends produced by gas dissolution foaming is reported. A systematic study of the effect of the processing condition is presented. Results show that the melt-blending results in a solid nanostructured material formed by nanometric TPU domains. The PMMA/ TPU foamed samples show a gradient cellular structure, with a homogeneous nanocellular core. In the core, the TPU domains act as nucleating sites, enhancing nucleation compared to pure PMMA and allowing the change from a microcellular to a nanocellular structure. Nonetheless, the outer region shows a gradient of cell sizes from nano- to micron-sized cells. This gradient structure is attributed to a non-constant pressure profile in the samples due to gas desorption before foaming. The nucleation in the PMMA/ TPU increases as the saturation pressure increases. Regarding the effect of the foaming conditions, it is proved that it is necessary to have a fine control to avoid degeneration of the cellular materials. Graded nanocellular polymers with relative densities of $0.16-0.30$ and cell sizes ranging $310-480 \mathrm{~nm}$ (in the nanocellular core) are obtained.

\section{Introduction}

The current demands of cost reductions have sharply increased the use of light-weight materials in many industrial sectors. In particular, the use polymer foams or cellular polymers is extremely widespread. Cellular polymers combine the properties

Dr. V. Bernardo, Dr. J. Martin-de Leon, I. Sanchez-Calderon,

Dr. M. A. Rodriguez-Perez

Cellular Materials Laboratory (CellMat)

Condensed Matter Physics Department

University of Valladolid

Campus Miguel Delibes, Paseo de Belén n7, 47011 Valladolid, Spain

E-mail: vbernardo@fmc.uva.es

Dr. E. Laguna-Gutierrez

Cell Mat Technologies S.L.

Paseo de Belén n9A, 47011 Valladolid, Spain

The ORCID identification number(s) for the author(s) of this article can be found under https://doi.org/10.1002/mame.201900428.

DOI: 10.1002/mame.201900428 of polymers with cost and weight reductions, meeting the requirements for a wide variety of applications..$^{[-4]}$ The key parameters determining the properties of cellular polymers are the density and cellular morphology. ${ }^{[5]}$ Thus, the research in cellular polymers is constantly evolving toward new and advanced structures that allow reaching enhanced performance. ${ }^{[6]}$

Graded cellular polymers, that is, materials with a gradient in their cellular structure and/or density, are one example of advanced structures. Some of the porous structures found in nature, such as wood or bones, present complex structures that confer them the properties required for their biological purpose. ${ }^{[7]}$ In the case of manufactured cellular polymers, it has been proved that a non-homogeneous structure can lead to better behavior for some specific applications, such as highenergy absorption,,$[8,9]$ acoustic absorption, ${ }^{[10]}$ or electromagnetic interference shielding. ${ }^{[11]}$ There are several strategies to produce cellular polymers with graded morphologies. One approach is the use of nucleating agents gradually distributed, such as in the work of Pinto et al. ${ }^{[12]}$ With a localized synthesis of the nanoparticles in the solid material, they reached a templated porous structure after foaming. In the work of Yu and coworkers, ${ }^{[13]}$ polymers were foamed in a nanoporous substrate that enhanced nucleation near the substrate, reaching a graded cellular structure. A gradient in the foaming parameters might also induce the formation of a non-homogeneous structure. For instance, Ngo et al. ${ }^{[14]}$ designed an experimental setup to generate nonconstant temperature profiles to induce the formation of graded structures. Another approach is related to the use of non-constant distributions of the blowing agent. Zhou and coworkers ${ }^{[15]}$ proposed the use of non-equilibrium concentration profiles in the gas dissolution foaming method. With this idea, Trofa et al. ${ }^{[16]}$ generated multi-graded cellular polymers by applying advanced time-variable gas concentration profiles.

In the way toward advanced structures, another promising research line is the reduction of the cell size, that is, the production of microcellular and nanocellular polymers. Particularly, nanocellular polymers have aroused great attention recently 
due to their new properties. It has been proved that the thermal conductivity through the gas phase can be reduced when the cell size moves to the nanoscale. ${ }^{[17-20]}$ Enhanced mechanical performance was also demonstrated in some nanocellular polymers. ${ }^{[21,22]}$ Further, it is possible to produce semi-transparent nanocellular polymers, ${ }^{[23,24]}$ among other interesting properties and applications. ${ }^{[25-27]}$ The challenge in the production of these systems is currently in the reduction of the density while keeping the cell size in the nanometric range.

Currently, the most interesting results to produce lowdensity nanocellular polymers have been achieved using poly(methyl methacrylate) (PMMA) foamed via a gas dissolution method. ${ }^{28-32]}$ Among the different strategies, the use of nanostructured polymer blends allows to produce low-density nanocellular materials at mild processing conditions. The blend of poly(methyl methacrylate)-poly(butyl acrylate)-poly(methyl methacrylate) (MAM) copolymer with PMMA $^{[33-36]}$ was proved recently to allow reaching relative densities of 0.23 and cell sizes of $350 \mathrm{~nm} \cdot{ }^{[37]}$ Another interesting system is the immiscible blend of PMMA with thermoplastic polyurethane (TPU) that results in a nanostructuration of the TPU phase, as shown by Wang and coworkers. ${ }^{[19]}$ Using a two-step gas dissolution foaming method with an extra cooling step, they obtained a very low-density nanocellular polymer with a relative density as low as 0.125 , while the cell size was only $205 \mathrm{~nm}$.

In this paper, we produce cellular polymers based on PMMA/ TPU blends that combine the two advanced structures previously mentioned. On the one hand, the samples produced in this work present a graded cellular structure thanks to the joint action of a non-equilibrium concentration profile and the addition of the TPU phase. On the other hand, the cell size moves from the micro- to the nanoscale. In addition, the materials present low relative densities. The effects of the saturation pressure and foaming conditions have been evaluated to gain knowledge about the foaming mechanisms taking place in these systems.

\section{Experimental Section}

\subsection{Materials}

PMMA PLEXIGLAS 7N, in the form of pellets, was provided by Evonik. This PMMA grade was characterized by a melt flow index (MFI) of $3.6 \mathrm{~g} / 10 \mathrm{~min}$ (obtained at $230{ }^{\circ} \mathrm{C}$ and $2.16 \mathrm{~kg}$ ) and a density of $1.19 \mathrm{~g} \mathrm{~cm}^{-3}$. The glass transition temperature, measured by DSC, was $109^{\circ} \mathrm{C}$. The molecular weight of the polymer (measured by GPC) was $M_{\mathrm{n}}=45 \mathrm{~kg} \mathrm{~mol}^{-1}$ and $M_{\mathrm{W}}=84 \mathrm{~kg} \mathrm{~mol}^{-1}$. The rheological properties of PMMA can be found in Section S1, Supporting Information.

TPU Estane BCX61 was kindly supplied by Lubrizol. The MFI of this TPU was $27.9 \mathrm{~g} / 10 \mathrm{~min}$ (determined at $230^{\circ} \mathrm{C}$ and $2.16 \mathrm{~kg}$ ), and the density was $1.19 \mathrm{~g} \mathrm{~cm}^{-3}$. This TPU was a semicrystalline polymer formed by hard (semicrystalline) and soft (amorphous) segments. The hard segments are characterized by a melting temperature at $151{ }^{\circ} \mathrm{C}$, while the glass transition of the soft segments was around $-44^{\circ} \mathrm{C}$ (determined by DSC). The glass transition of the hard segments was not detected in the DSC experiment. The rheological properties of TPU can be found in Section S1, Supporting Information.
For the gas dissolution foaming experiments, the blowing agent used was medical grade carbon dioxide $\left(\mathrm{CO}_{2}\right)$ of $99.9 \%$ purity.

\subsection{Solid Blends Production}

A PMMA/TPU blend with a $2 \mathrm{wt} \%$ of TPU was melt blended by extrusion. The equipment used was a twin-screw extruder with $\mathrm{L} / \mathrm{D}$ equal to 24 and screw diameter equal to $25 \mathrm{~mm}$ (model COLLIN TEACH-LINE ZK 25T). PMMA and TPU were dried in a vacuum oven at $50^{\circ} \mathrm{C}$ for at least $12 \mathrm{~h}$ before the extrusion. The blend was extruded with a temperature range from $150{ }^{\circ} \mathrm{C}$ in the hopper to $190{ }^{\circ} \mathrm{C}$ in the die, while the screw speed was equal to $40 \mathrm{rpm}$. The blend obtained from the first extrusion cycle was cooled in a water bath and afterward pelletized. The pellets were dried, and then the material was extruded again under the same processing parameters to assure homogeneity. In the second extrusion cycle, the extruded filament was set aside to let cool at room temperature. The cylindrical filament (that presents an average diameter of 3-4 mm) was cut to samples of $30 \mathrm{~mm}$ in length for the foaming experiments.

The as-received PMMA was processed using the same extrusion conditions to obtain samples for the foaming experiments.

\subsection{Gas Dissolution Foaming Experiments}

Foaming experiments were conducted in a high-pressure vessel, model PARR 4681 (Parr Instrument Company). The pressure was controlled with an accurate pressure pump model SFT-10 (Supercritical Fluid Technologies, Inc.). A clamp heater of $1200 \mathrm{~W}$, regulated via a CAL 3300 temperature controller, adjusted the temperature of the vessel. The procedure used for all the experiments was the so-called two-step foaming process. ${ }^{[38]}$ First, samples were put into the pressure vessel at a constant $\mathrm{CO}_{2}$ pressure (ranging from 6 to $20 \mathrm{MPa}$ in this work) at a constant temperature $\left(25^{\circ} \mathrm{C}\right)$ for the saturation stage. Saturation time was $24 \mathrm{~h}$ in all the experiments except in the case of $6 \mathrm{MPa}$, in which the saturation time was $48 \mathrm{~h}$. The selected times were overestimated from data available at these pressures for sheets ${ }^{[35,39]}$ to ensure full saturation in the cylindrical samples. After saturation, the pressure was quickly released using an electrovalve. The pressure drop rate during the first pressure drop increased with the saturation pressure: $0.7,15,36$, and $56 \mathrm{MPa} \mathrm{s}^{-1}$ for pressures of $6,10,15$, and $20 \mathrm{MPa}$, respectively. Then, the samples were removed from the vessel and immersed in a thermal bath at the desired temperature $\left(90\right.$ or $100{ }^{\circ} \mathrm{C}$ ) for the foaming stage. Foaming time was $0.5,1$, or $2 \mathrm{~min}$. Between the release of pressure and the immersion of the samples in the thermal bath, there was a time gap of $2.5 \mathrm{~min}$.

\subsection{Characterization}

\subsubsection{Nanostructuration of the PMMA/TPU Blend}

The morphology of the solid PMMA/TPU blend was investigated using scanning electron microscopy (SEM). Images were collected with an SEM microscope FlexSEM 1000 VP-SEM (Hitachi 


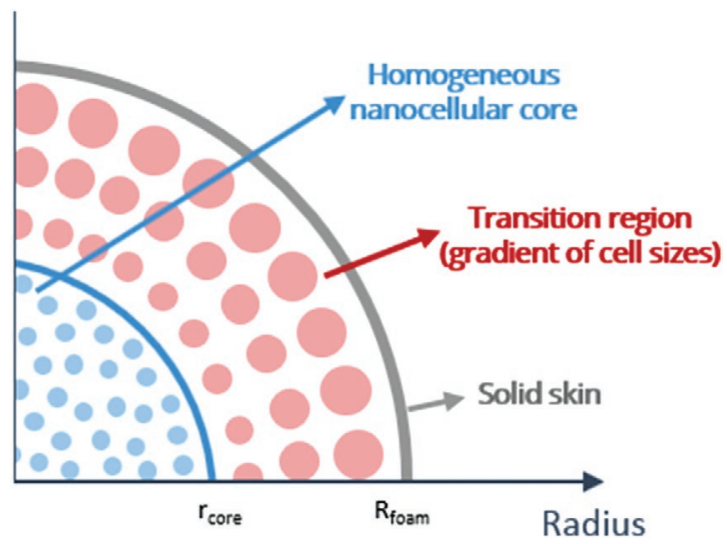

Figure 1. Schematic structure of the cylindrical samples obtained in this work.

High-Technologies). To prepare the solid materials for this analysis, they were cooled in liquid nitrogen and fractured. Then, a chemical etching with tetrahydrofuran (THF) was performed by immersing the fractured surface in THF for $30 \mathrm{~min}$. This solvent dissolved the TPU phase quickly, so it selectively removed the TPU domains of the surface, while the PMMA matrix was not affected during this time. After the etching, the surface was coated with gold using a sputter coater model SCD 005 (Balzers Union). SEM images were analyzed with the Image//FIJI software. The density of the TPU domains $\left(N_{\mathrm{d}}\right)$ was determined according to Equation (1), where $n_{\mathrm{d}}$ is the number of TPU domains in a region of area $A_{\mathrm{d}}$. The domain size $\left(\varphi_{\mathrm{d}}\right)$ was calculated by averaging the size measurements of a satisfactory number of domains.

$N_{\mathrm{d}}=\left(\frac{n_{\mathrm{d}}}{A_{\mathrm{d}}}\right)^{3 / 2}$

\subsubsection{Density}

A gas pycnometer model AccuPyc II 1340 (Micromeritics) was used to measure the density of the solid materials. On the other hand, the water displacement method based on Archimedes' principle was used to measure the density of the foamed samples using a density determination kit for an AT261 Mettler-Toledo balance. The samples of this work present a gradient structure as shown schematically in Figure 1. Then, the density of the foamed samples was determined twice. First, the density of the complete foamed sample was measured and the relative density of the global sample $\left(\rho_{\mathrm{r}, \mathrm{g}}\right)$ was determined. Then, the density of the homogeneous core (blue region in Figure 1) was determined by removing the transition region with a polisher model LaboPOl2-LaboForce3 (Struers) and measuring the density in the resultant sample. The thickness of the transition region to be removed $\left(R_{\text {foam }}-r_{\text {core }}\right.$ in Figure 1) was determined with SEM image analysis.

\subsubsection{Cellular Structure}

The cellular structure was investigated using an SEM, FlexSEM 1000 VP-SEM (Hitachi High-Technologies). Previously, the foamed samples were cooled in liquid nitrogen and fractured, and then coated with gold using a sputter coater model SCD 005 (Balzers Union). To fully characterize the gradient structure of the samples (as that of the scheme of Figure 1), SEM images were taken at different distances along the sample radius. To analyze the images and quantify the structural parameters that characterized the cellular structure at every point, a tool based on the software ImageJ/FIJI ${ }^{[40]}$ was used. First, the cell size distribution was measured, from which the average cell size in $3 \mathrm{D}(\varphi)$ and the standard deviation coefficient of the cell size distribution (SD) were obtained (3D values were obtained by multiplying the $2 \mathrm{D}$ values by the correction factor $1.273^{[40]}$ ). Cell density $\left(N_{\mathrm{v}}\right)$ was determined using Kumar's method ${ }^{[41]}$ according to Equation (2), where $A$ is the area analyzed and $n$ is the number of cells in that area. In every region, more than 200 cells were analyzed.

$N_{\mathrm{v}}=\left(\frac{n}{A}\right)^{3 / 2}$

In the core of the sample, that presents homogeneous cells, the cell nucleation density $\left(N_{0}\right)$ was determined using Equation (3) using the relative density of the core $\rho_{\mathrm{r}, \mathrm{c}}$.

$N_{0}=\frac{N_{\mathrm{v}}}{\rho_{\mathrm{r}, \mathrm{c}}}$

\section{Results and Discussion}

\subsection{Nanostructuration of the PMMA/TPU Blend}

Figure 2a shows the SEM image corresponding to the fracture surface of the solid PMMA/TPU blend after the etching process with THF. Nanometric holes are observed all along the sample, indicating the former presence of spherical TPU domains that are dissolved during the etching. Therefore, the immiscible blend of PMMA and TPU results in the formation of a nanostructure in which the TPU is dispersed forming nanometric domains. The number of the holes per unit of volume, that is, the TPU domain density, was determined to be $3.3 \times 10^{13}$ domains $/ \mathrm{cm}^{3}$. This volumetric density is high enough to promote the formation of sub-micro and nanocellular structures. The average size of the domains is $89 \mathrm{~nm}$, and the domain size distribution is represented in Figure $2 \mathrm{~b}$. Note that the real size of the domains is not measured, but assumed to be equal to the size of the hole remaining after the dissolution of the TPU phase. Then, it is plausible to claim that the TPU domain sizes provided in Figure $2 \mathrm{~b}$ are an upper limit of the real TPU domain sizes that should be smaller than $89 \mathrm{~nm}$ on average. Up to the precision of our measurements, there are no significant differences in the nanostructuration observed through the sample thickness.

\subsection{Effect of the Addition of TPU}

To evaluate the effect of the addition of TPU, a single foaming experiment was performed. Saturation pressure was fixed at 

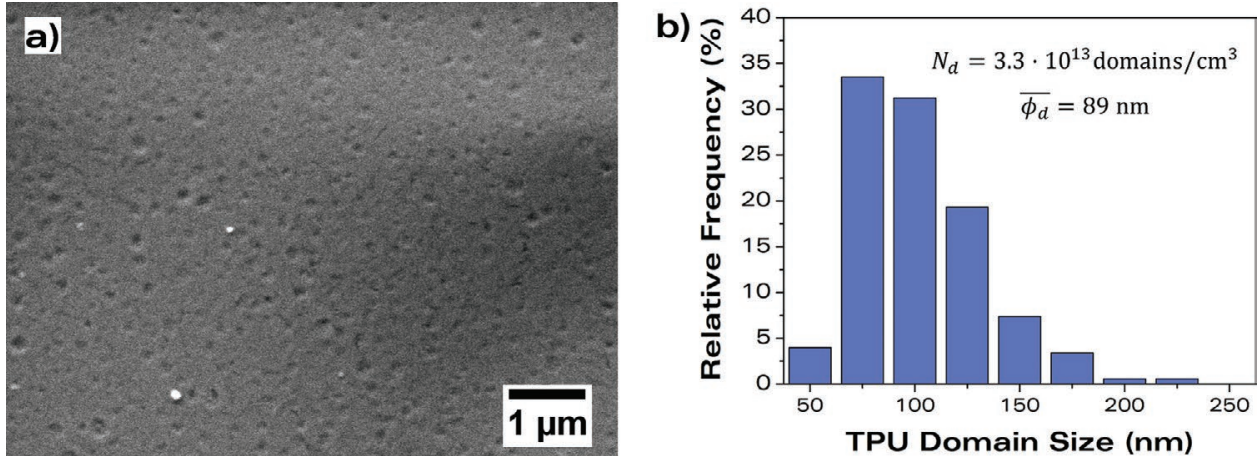

Figure 2. a) SEM image of the etched fracture of the solid PMMA/TPU blend, showing the nanostructuration, and b) domain size distribution, domain density, and average domain size.

Table 1. Amount of gas uptake, relative density, and cell nucleation densities in the core of the PMMA and the PMMA/TPU cellular samples produced at $15 \mathrm{MPa}$ of saturation pressure and foaming at $100^{\circ} \mathrm{C}$ during $1 \mathrm{~min}$.

\begin{tabular}{lcccc}
\hline Sample & $\begin{array}{c}\text { Gas uptake } \\
\text { [wt\%] }\end{array}$ & $\begin{array}{c}\text { Relative density } \\
\text { (global) }\end{array}$ & $\begin{array}{c}\text { Relative density } \\
\text { (core) }\end{array}$ & $\begin{array}{c}N_{0, \text { core }} \\
{[\text { nuclei/cm }}\end{array}$ \\
\hline PMMA & 28.0 & $0.12 \pm 0.01$ & $0.15 \pm 0.01$ & $4.7 \times 10^{11}$ \\
PMMA/TPU & 27.2 & $0.17 \pm 0.02$ & $0.18 \pm 0.01$ & $9.3 \times 10^{13}$ \\
\hline
\end{tabular}

$15 \mathrm{MPa}$, while foaming was carried out at a temperature equal to $100{ }^{\circ} \mathrm{C}$ during $1 \mathrm{~min}$. The pressure was selected to be low enough to prevent excessive homogeneous nucleation in the PMMA matrix that could hide the effect of the TPU.

Table 1 collects the amount of gas uptake by the PMMA and the PMMA/TPU blend at $15 \mathrm{MPa}$ of saturation pressure. The pure polymer absorbs as much as $28 \mathrm{wt} \%$ of $\mathrm{CO}_{2}$, whereas the PMMA/TPU blend absorbs a smaller amount of gas because at these conditions TPU absorbs around $18 \mathrm{wt} \%$ of $\mathrm{CO}_{2}$ (measured in a pure TPU sample), less than PMMA. Then, the changes detected under the addition of TPU would not be due to an increase in the $\mathrm{CO}_{2}$ solubility. In addition, the desorption diffusivity of the two materials is very similar (see Section S2, Supporting Information).

Figure 3 shows the representative SEM images taken at increasing distances from the center of the sample of the PMMA and the PMMA/TPU samples. The quantitative analysis of the cellular structure (cell size and cell density) throughout the sample radius is plotted in Figure 4. As commented in Figure 1, the samples present a gradient structure (Figure 3): the cell nucleation density decreases (Figure 3a) and the cell size increases (Figure 3b) toward the border of the sample. The effect is more noticeable in the PMMA/TPU blend. The relative densities (global and core) of the two foamed samples are included in Table 1. It is observed that the PMMA sample shows smaller densities, even though the addition of TPU reduces the viscosity of the PMMA/TPU blend slightly (see rheological properties of PMMA/TPU in Section S1, Supporting Information). Also, the global density is smaller than the core density, the differences around $10-20 \%$. Then, there also exists a gradient in the density along the sample radius.

The PMMA sample presents a microcellular structure, with pores of some microns (around 2-4 $\mu \mathrm{m}$ ), while the PMMA/ TPU system shows a nanocellular structure in the core (cell

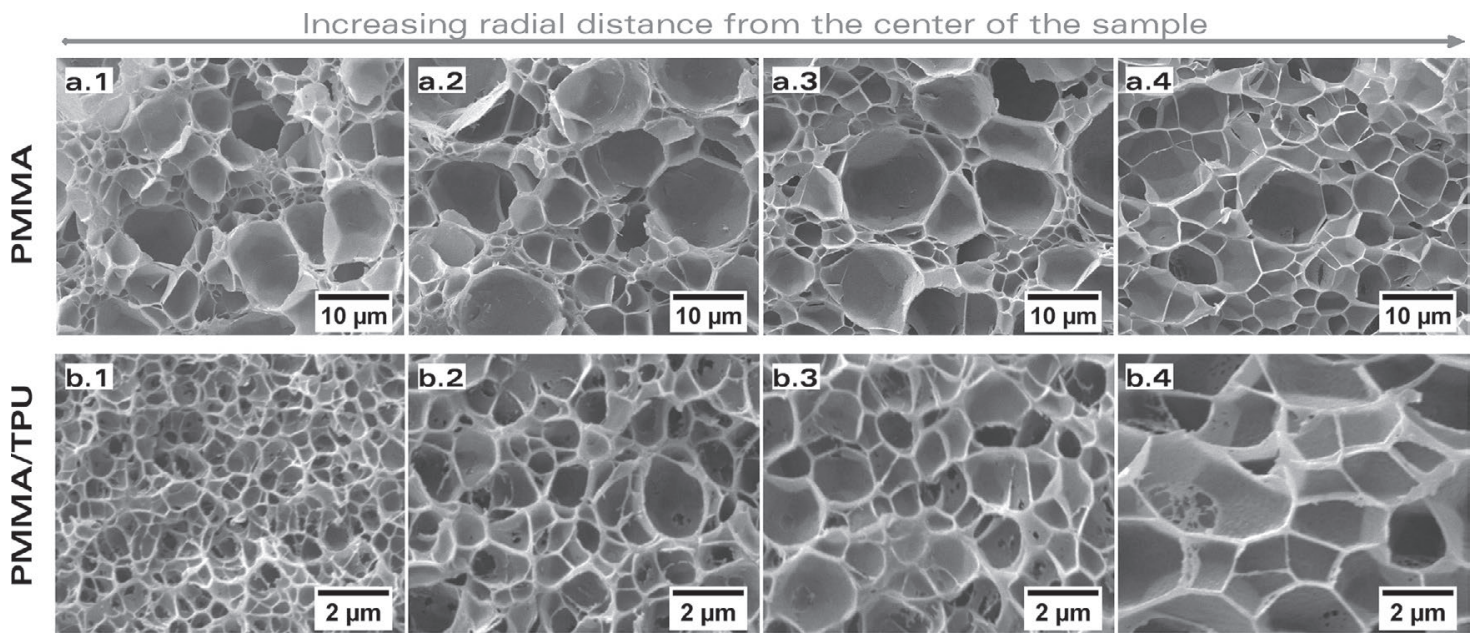

Figure 3. Representative SEM images of the cellular samples produced at $15 \mathrm{MPa}$ of saturation pressure and foamed at $100^{\circ} \mathrm{C}$ during 1 min: a) $\mathrm{PMMA}$ and b) PMMA/TPU. Each image is taken at increasing distance from the center of the sample (d) (a.1 and b.1: $d<40 \%$ (CORE); a.2 and b.2: $d \approx 50 \%$; a. 3 and b. $3: d \approx 70 \%$; a.4 and b. $4: d>90 \%$ ). 
a)

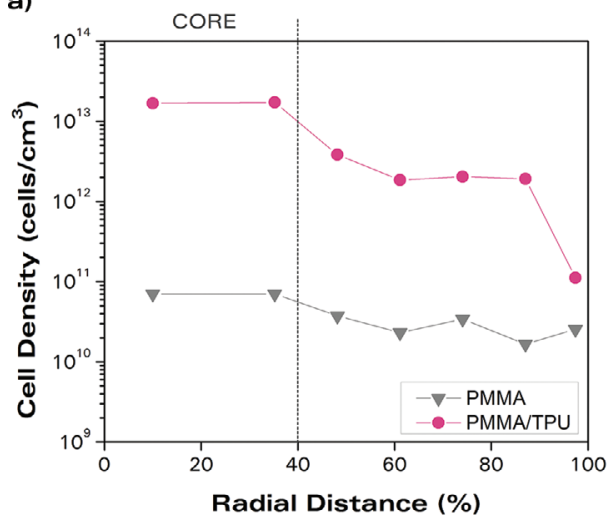

b)

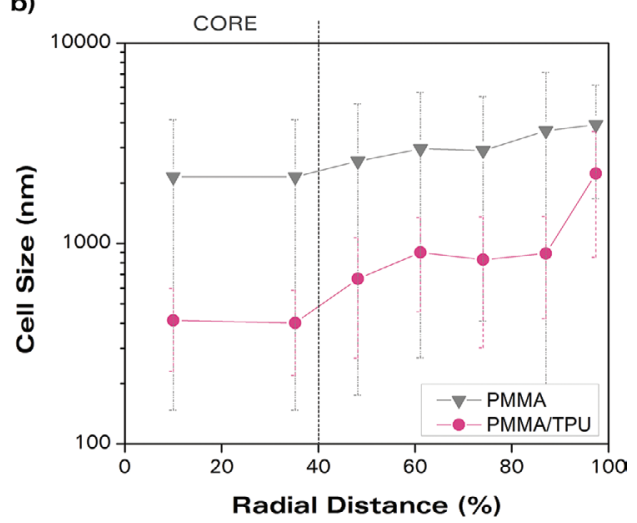

Figure 4. a) Cell density and b) cell size of the PMMA and the PMMA/TPU cellular samples produced at 15 MPa of saturation pressure and foamed at $100{ }^{\circ} \mathrm{C}$ during $1 \mathrm{~min}$, as a function of the radial distance from the center of the sample (0\% is the center of the sample and $100 \%$ is the border). Error bars in (b) indicate SD of the cell size distribution.

size of $400 \mathrm{~nm}$ ) that gradually becomes microcellular toward the border. The so-called core region covers around $40 \%$ of the sample radius (Figure 4), or in other words, roughly $16 \%$ of the volume of the sample. In this core region, the PMMA/TPU sample is characterized by cell sizes around $400 \mathrm{~nm}$, a relative density of 0.18 , and a cell nucleation density exceeding $7 \times$ $10^{13}$ nuclei $/ \mathrm{cm}^{3}$ (Table 1 ). The nucleation density is of the same order of magnitude as the volumetric density of TPU domains in the solid (Figure 2). Then, we conclude that the addition of TPU produces a clear nucleating effect in PMMA by enhancing the nucleation and reducing the cell size.

Concerning the gradient structure, it is observed that in the PMMA/TPU material the cell density increases in two orders of magnitude from the border to the core of the sample (Figure 4a). The possible mechanisms under the appearance of this gradient of cell sizes will be discussed in the next section.

\subsection{Effect of the Saturation Pressure}

The effect of the saturation pressure in the PMMA/TPU blend was evaluated by performing four saturation experiments at different pressures: $6,10,15$, and $20 \mathrm{MPa}$, while keeping the foaming conditions constant $\left(100{ }^{\circ} \mathrm{C}\right.$ and $\left.1 \mathrm{~min}\right)$. Figure 5 shows the SEM images of the samples produced for this study. Only the core regions are shown for the sake of comparison, but all the samples present a gradient cellular structure from the core to the border as already observed in Figure 2. Table 2 summarizes the densities of these materials (both the core and the global density) and the cell nucleation densities calculated in the core region, whereas Figure 6 shows the cell size (Figure 6a) and the cell density (Figure 6b) for the different pressures as a function of the distance from the center of the sample.

Focusing on the core region of the samples, at $6 \mathrm{MPa}$, we observe a microcellular structure. When pressure increases from 6 to $10 \mathrm{MPa}$, nucleation density changes from $2 \times 10^{12}$ to $7 \times 10^{13}$ nuclei $/ \mathrm{cm}^{3}$ (Table 2 ), and as a consequence, cell size moves from the micro to the nanoscale $(460 \mathrm{~nm})$. For a saturation pressure of $15 \mathrm{MPa}$, nucleation is slightly higher than at $10 \mathrm{MPa}$, resulting in similar cell size (400 nm) (Figure 6b). At $20 \mathrm{MPa}$, there is no significant change in nucleation (Table 2), but the structure becomes less homogeneous. At low magnification, some large pores are detected in Figure 5d, and at high magnification (inset of Figure $5 \mathrm{~d}$ ), a very heterogeneous structure is found, with tiny pores and other pores near the micron, which in average results in a cell size around $360 \mathrm{~nm}$. The relative densities of these samples are summarized in Table 2. It can be said that the values are almost constant with the saturation pressure, ranging from 0.18 to 0.20 in the core region.

The conclusion from the analysis of the core region is that the heterogeneous nucleation effect due to the addition of TPU is pressure-dependent. This is a surprising result, since in other heterogeneous systems such as in blends with nanoparticles ${ }^{[42]}$ or with nanometric micelles, ${ }^{[35]}$ the heterogeneous nucleation was proved to be predominant over a wide range of pressures.
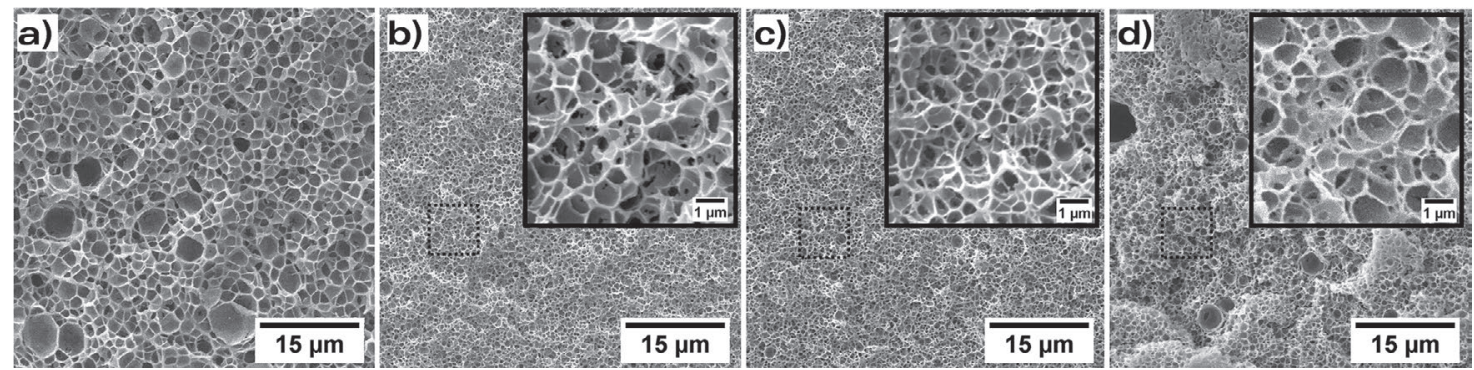

Figure 5. SEM images of the core of the PMMA/TPU samples produced at different saturation pressures: a) $6 \mathrm{MPa}$, b) $10 \mathrm{MPa}$, c) $15 \mathrm{MPa}$, and d) $20 \mathrm{MPa}$. (Foaming was carried out at $100^{\circ} \mathrm{C}$ during $1 \mathrm{~min}$.) 
Table 2. Relative densities and cell nucleation densities in the core of the PMMA/TPU cellular samples produced at various saturation pressures and foaming at $100{ }^{\circ} \mathrm{C}$ during $1 \mathrm{~min}$.

\begin{tabular}{lcccc}
\hline Sample & $\begin{array}{c}\text { Saturation } \\
\text { pressure }\end{array}$ & $\begin{array}{c}\text { Relative density } \\
\text { (global) }\end{array}$ & $\begin{array}{c}\text { Relative density } \\
\text { (core) }\end{array}$ & $\begin{array}{c}N_{0, \text { core }} \\
\text { [nuclei/cm } / \mathrm{cm}^{3} \text { ] }\end{array}$ \\
\hline PMMA/TPU & 6 & $0.16 \pm 0.01$ & $0.19 \pm 0.01$ & $2.3 \times 10^{12}$ \\
PMMA/TPU & 10 & $0.16 \pm 0.01$ & $0.18 \pm 0.01$ & $7.1 \times 10^{13}$ \\
PMMA/TPU & 15 & $0.17 \pm 0.01$ & $0.18 \pm 0.01$ & $9.3 \times 10^{13}$ \\
PMMA/TPU & 20 & $0.18 \pm 0.01$ & $0.20 \pm 0.01$ & $9.5 \times 10^{13}$ \\
\hline
\end{tabular}

However, this is not the case for the PMMA/TPU system. The nucleation observed at $6 \mathrm{MPa}$ is smaller than the TPU domain density (Figure 2) by one order of magnitude. Therefore, at this low pressure, we cannot claim that heterogeneous nucleation is taking place in all the TPU domains. However, the presence of the TPU nano-domains does enhance nucleation at $6 \mathrm{MPa}$ because the nucleation in the PMMA/TPU system is higher than in the pure PMMA (at $15 \mathrm{MPa}$, the nucleation in PMMA was $10^{11}$ nuclei $/ \mathrm{cm}^{3}$, (Table 1 ) while in the PMMA/TPU blend at $6 \mathrm{MPa}$ is $10^{12}$ nuclei $\left./ \mathrm{cm}^{3}\right)$. Then, we conclude that the TPU domains are partially acting as nucleating sites, but the efficiency of the nucleation depends on the saturation pressure.

To explain the dependence of nucleation with the pressure, we can consider two ideas. First, the nucleation in the PMMA/ TPU system could be not purely heterogeneous, but a mixture of homogeneous nucleation in the PMMA phase and heterogeneous nucleation in the TPU. As nucleation does depend on the pressure in the pure PMMA, this combined effect would explain the dependency observed in the PMMA/TPU sample. Also, it is possible to explain results taking into account the critical radius, $r_{c}{ }^{[43-45]}$ defined according to Equation (4), where $\gamma$ is the surface tension of the system and $\Delta p$ is the pressure gradient. It is known that the ratio between the radius of the nucleating species, $R$, and the critical radius plays a key role in the reduction of the energy barrier in a heterogeneous nucleation process. ${ }^{[46]}$ As the critical radius varies with pressure (Equation (4)), it is understandable that the efficiency of the nucleation could also depend on pressure. For a low pressure, $r_{\mathrm{c}}$ might be too high compared to the size of the TPU domains, and then the efficiency of the nucleation is poor. As pressure increases, $r_{\mathrm{c}}$ decreases, so the two radii get closer and the efficiency of the nucleation increases.

$r_{\mathrm{c}}=\frac{2 \gamma}{\Delta p}$

With these results, we can aim at explaining the gradient cellular structures observed in these samples. As the analysis of the solids showed that the dispersion of the TPU phase was homogeneous throughout the sample thickness, it is unlikely that the gradient structure is due to a heterogeneous distribution of the TPU phase in the solid. Then, and based on the results observed at different pressures, we suggest that this phenomenon is a consequence of the fast diffusion of the gas out of the cylindrical samples. Once the pressure is released, the gas is leaving the samples quickly, and there is a pressure gradient inside the sample when foaming starts. That is, there exists a non-equilibrium concentration profile from the center toward the border of the sample that could lead to graded structures, ${ }^{[15,16]}$ and in fact, in the pure PMMA, a slight gradient is also observed (Figures 3 and 4) (recall that both PMMA and PMMA/TPU had similar desorption diffusivities [Section S2, Supporting Information], so similar gas concentration profiles would appear in the two materials). Due to the fact that nucleation depends on pressure in the PMMA/TPU systems, gradient nucleation takes place in the PMMA/TPU sample, causing a sharp gradient in cell sizes. Figure 7 schematically shows the mechanisms involved in the formation of the nanocellular graded structure. To further prove this idea, we have performed some additional measurements along the sample length, showing that there is also a gradient structure (these results can be found in Section S3, Supporting Information). In addition, we also proved that the gradient structure appears in blends with a smaller TPU concentration, supporting that the TPU is responsible for the appearance of such structure (see Section S5, Supporting Information).

Regarding the effect of pressure on the gradient structure, it is observed that the homogeneous core is smaller at $6 \mathrm{MPa}$ (Figure 6), supporting the previous discussion about the effect of the pressure. Among the three other pressures, the cell sizes and cell densities follow the same trends as in the core; that is, cell size decreases with saturation pressure along all the sample radius (Figure 6).
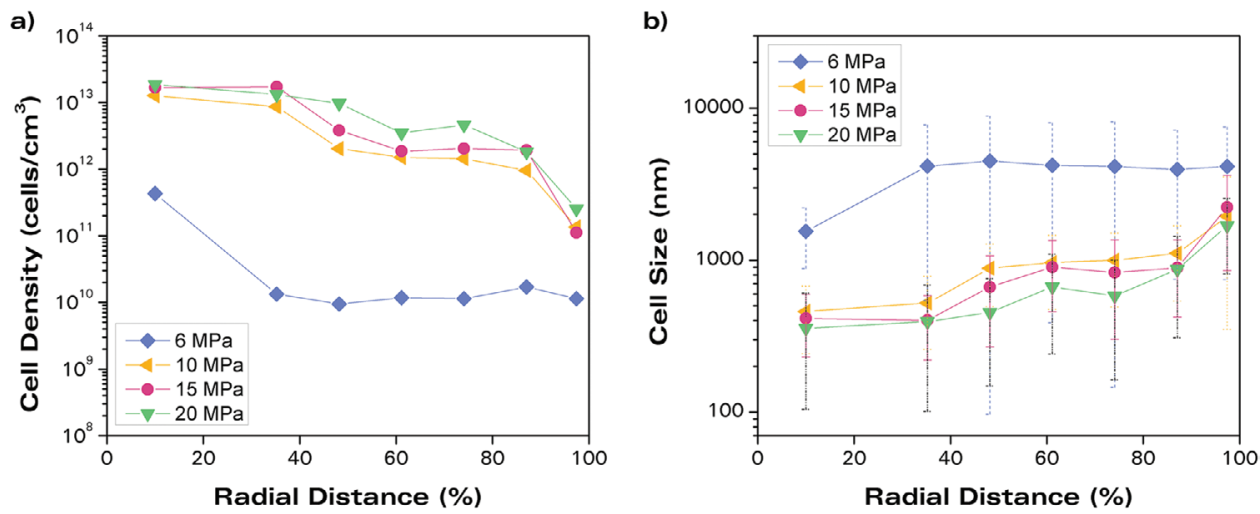

Figure 6. a) Relative density and b) cell nucleation density (left axis) and cell size (right axis) as a function of the saturation pressure for the PMMA/ TPU samples. Error bars in (b) indicate SD of the cell size distribution. 
a) Concentration profile inmediatelly after saturation

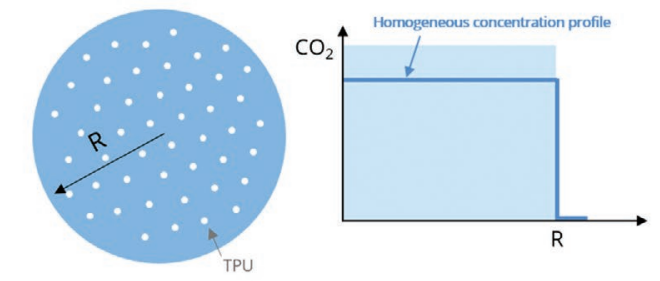

c) Nucleation gradient in the TPU phase due to $\mathrm{CO}_{2}$ profile

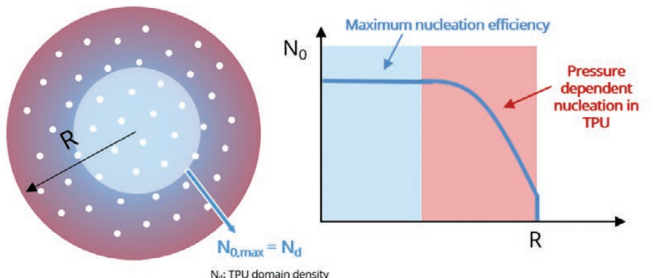

b) Concentration profile after desorption time before foaming
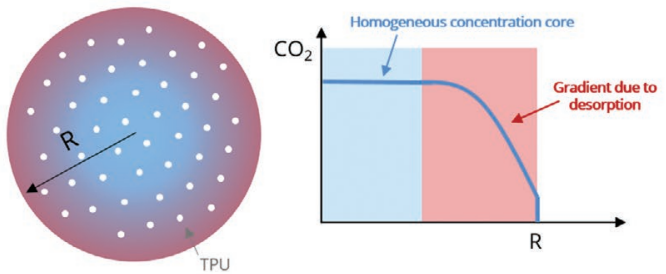

d) Cell size gradient in the foamed samples due to gradient nucleation

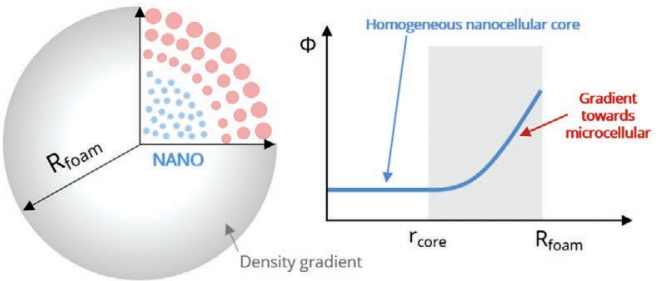

Figure 7. Schematic representation of our hypothesis of the formation of the graded cellular structure with a nanocellular core region in the PMMA/ TPU systems.

\subsection{Effect of the Foaming Conditions}

To further investigate the foaming behavior of the PMMA/TPU system, additional foaming experiments were performed. In this case, the saturation pressure was fixed at $15 \mathrm{MPa}$, as at this pressure the best results were found in the previous section. Meanwhile, the foaming parameters were varied. Five sets of foaming conditions (temperature/time) were used and compared with the results of the previous section $\left(100{ }^{\circ} \mathrm{C} / 1 \mathrm{~min}\right)$ : $90{ }^{\circ} \mathrm{C} / 0.5 \mathrm{~min}, 90^{\circ} \mathrm{C} / 1 \mathrm{~min}, 90^{\circ} \mathrm{C} / 2 \mathrm{~min}, 100{ }^{\circ} \mathrm{C} / 0.5 \mathrm{~min}$, and $100^{\circ} \mathrm{C} / 2 \mathrm{~min}$. The cellular structure in the core of the materials produced is shown in Figure 8. In this section, we will focus on analyzing the structure in the nanocellular core. However, all the samples presented a gradient structure as in previous studies (see details of the cell density and the cell size as a function of the radial distance for the different samples produced in Figure S7, Supporting Information). Table 3 collects the density of these samples, the average cell size in the core, the standard deviation of the cell size distribution and the cell nucleation density calculated in the core.
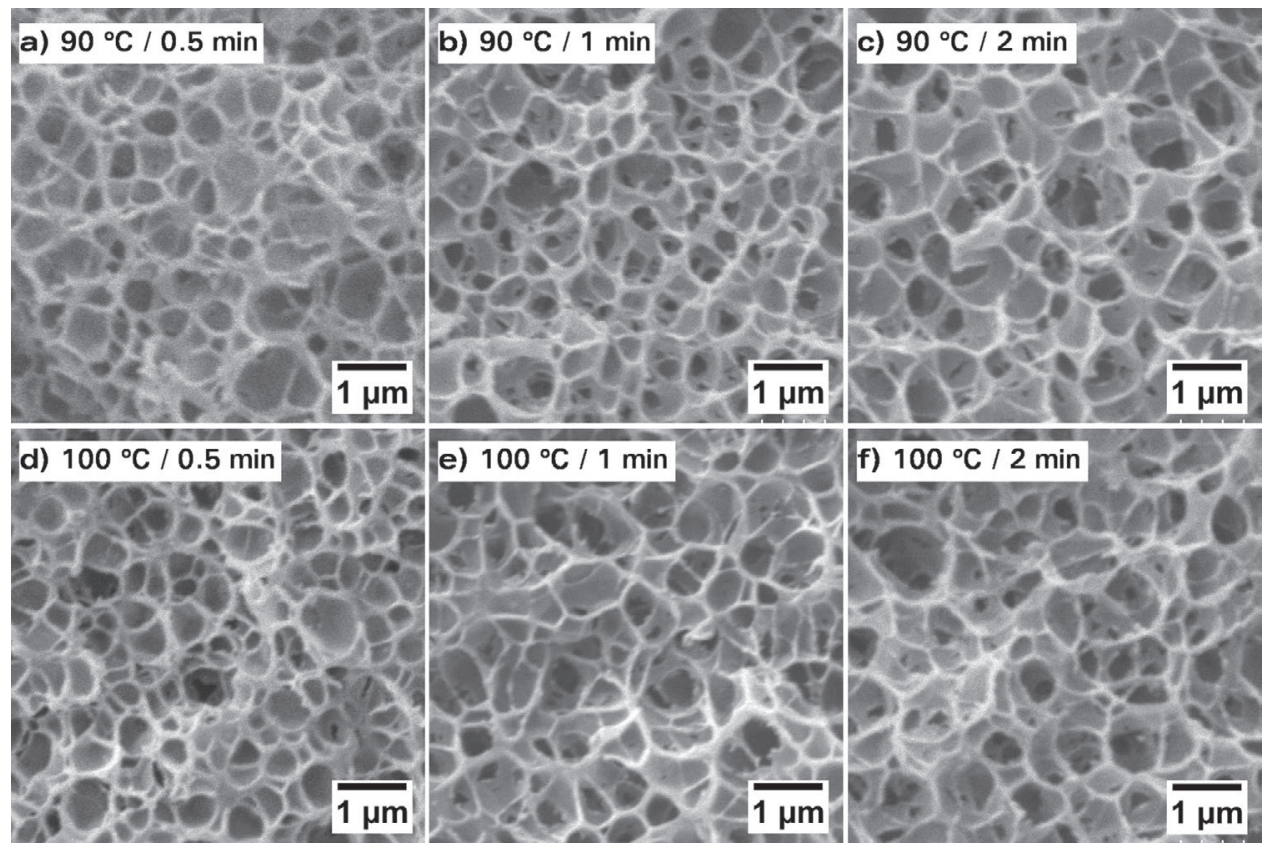

Figure 8. SEM images taken in the center of the PMMA/TPU samples produced at various foaming conditions: a) $90^{\circ} \mathrm{C} / 0.5 \mathrm{~min}$, b) $90{ }^{\circ} \mathrm{C} / 1 \mathrm{~min}$, c) $90^{\circ} \mathrm{C} / 2 \mathrm{~min}$, d) $100^{\circ} \mathrm{C} / 0.5 \mathrm{~min}$, e) $100^{\circ} \mathrm{C} / 1 \mathrm{~min}$, and f) $100^{\circ} \mathrm{C} / 2 \mathrm{~min}$. (Saturation pressure was equal to $15 \mathrm{MPa}$.) 
Table 3. Relative densities, cell size, and cell nucleation densities in the core of the PMMA/TPU cellular samples produced at several foaming conditions after saturation and $15 \mathrm{MPa}$.

\begin{tabular}{|c|c|c|c|c|c|c|}
\hline Foaming temperature $\left[{ }^{\circ} \mathrm{C}\right]$ & Foaming time [min] & Relative density (global) & Relative density (core) & $N_{0, \text { core }}\left[\right.$ nuclei per $\mathrm{cm}^{3}$ ] & $\varphi_{\text {core }}[\mathrm{nm}]$ & $S D_{\text {core }}[\mathrm{nm}]$ \\
\hline 90 & 0.5 & $0.24 \pm 0.00$ & $0.30 \pm 0.00$ & $6.1 \times 10^{13}$ & 370 & 160 \\
\hline 90 & 1 & $0.17 \pm 0.01$ & $0.20 \pm 0.01$ & $9.2 \times 10^{13}$ & 400 & 180 \\
\hline 90 & 2 & $0.14 \pm 0.01$ & $0.16 \pm 0.01$ & $6.6 \times 10^{13}$ & 480 & 220 \\
\hline 100 & 0.5 & $0.20 \pm 0.00$ & $0.30 \pm 0.00$ & $9.6 \times 10^{13}$ & 320 & 180 \\
\hline 100 & 1 & $0.17 \pm 0.01$ & $0.18 \pm 0.01$ & $9.3 \times 10^{13}$ & 410 & 180 \\
\hline 100 & 2 & $0.19 \pm 0.01$ & $0.18 \pm 0.01$ & $6.4 \times 10^{13}$ & 450 & 250 \\
\hline
\end{tabular}

At $90{ }^{\circ} \mathrm{C}$, an increase in the foaming time from 0.5 to $2 \mathrm{~min}$ causes a significant reduction of the relative density (from 0.30 to 0.16 in the core), but at the same time the cell size increases from 370 to $480 \mathrm{~nm}$ (Table 3). The maximum nucleation is observed at $1 \mathrm{~min}$, and at $2 \mathrm{~min}$, the nucleation is reduced (Table 3). From these observations, we conclude that increasing foaming time at $90{ }^{\circ} \mathrm{C}$ up to 2 min causes cell coalescence because the cell nucleation density measured is smaller and the cell size is higher. This effect allows a reduction of the density, but at the expense of increasing the cell size. At $100{ }^{\circ} \mathrm{C}$, the cell nucleation density is observed to be maximum between 0.5 and $1 \mathrm{~min}$, whereas at $2 \mathrm{~min}$, it is reduced (Table 3). The cell size increases as foaming time does, from 320 to $450 \mathrm{~nm}$. Relative density reduces from 0.5 to $1 \mathrm{~min}$, but increasing time to $2 \mathrm{~min}$ does not reduce the density further, even though the cell size increases. Then, at $100{ }^{\circ} \mathrm{C}$, a foaming time of $2 \mathrm{~min}$ also degenerates the cellular structure (higher cell size and smaller cell nucleation density).

In general, similar cell sizes and nucleation densities are detected at 90 and $100{ }^{\circ} \mathrm{C}$, but we observe that at $100{ }^{\circ} \mathrm{C}$, expansion occurs faster; that is, at $0.5 \mathrm{~min}$, the density is smaller and also the cell nucleation density is already the maximum possible.

We can conclude that the foaming parameters are essential to obtain the desired structures in the PMMA/TPU blends. In particular, foaming time is crucial, since a slight increase can induce coalescence of the cellular structure. In other PMMAbased nanocellular polymers, the effect of foaming time (even $5 \mathrm{~min}$ ) was not so significant. ${ }^{[28]}$ One possible rationale to explain the narrow processing window in the production of nanocellular polymers with the PMMA/TPU blend is the low viscosity of the PMMA matrix used in this research. Another reason might be related to the presence of the TPU domains that are around $90 \mathrm{~nm}$ in size. They should be placed in the cell walls, and they could be weak points for cell wall rupture when the polymer is stretched to the low densities achieved in this paper.

\section{Conclusions}

Low-density nanocellular polymers with a gradient cellular structure based on PMMA/TPU blends have been produced via a gas dissolution foaming process. PMMA was melt blended with $2 \mathrm{wt} \%$ of TPU by extrusion. As a result of the dispersion of the TPU during the extrusion on the immiscible blend, the solid material presents a nanostructuration formed by nanometric TPU domains in a density higher than $10^{13}$ domains $/ \mathrm{cm}^{3}$.
Results show that the PMMA/TPU samples present a gradient cell size from the core to the border, from a homogeneous nanocellular core to a microcellular transition region. In the nanocellular core of the samples, the addition of TPU induces an increase of the cell nucleation density of three orders of magnitude and a reduction of the cell size, going from a microcellular structure in the pure PMMA to a nanocellular material in the PMMA/TPU at $15 \mathrm{MPa}$ of saturation pressure. The nucleation density obtained in the PMMA/TPU sample is similar to the TPU domain density measured in the solids, showing that the dispersed TPU domains in the PMMA matrix are acting as nucleating agents.

An increase of the saturation pressure from 6 to $20 \mathrm{MPa}$ causes an increase in the cell nucleation density in the PMMA/ TPU system. This result indicates that the heterogeneous nucleation in the TPU domains is not predominant at all pressures. Then, we hypothesize that the formation of the gradient of cell sizes is due to a gradient nucleation in the PMMA/TPU samples, caused by a non-constant gas concentration profile in the samples due to the desorption of gas before the foaming step.

Finally, the analysis of the foaming conditions shows that an excessive foaming time can lead to the appearance of degeneration mechanisms in the PMMA/TPU nanocellular polymers, such as coalescence, causing an increase of the cell size.

\section{Supporting Information}

Supporting Information is available from the Wiley Online Library or from the author.

\section{Acknowledgements}

Financial assistance from Ministerio de Economía y Competitividad, FEDER, UE (MAT2015-69234-R) and the Junta de Castile and Leon (VA275P18) are gratefully acknowledged. Financial support from the FPU grant FPU14/02050 (V.B.) from the Ministerio de Educación, Cultura y Deporte and the Junta of Castile and Leon grant (J.M.-d-L.) are gratefully acknowledged. Financial assistance from EREN (Ente Regional de la Energía de Castilla y León EREN_2019_L4_UVA) is gratefully acknowledged.

\section{Conflict of Interest}

The authors declare no conflict of interest. 


\section{Keywords}

gas dissolution foaming, graded structures, nanocellular polymers, nanostructuration

Received: July 9, 2019

Revised: September 26, 2019

Published online: October 21, 2019

[1] H. Zhang, Q. Yan, W. Zheng, Z. He, Z. Yu, ACS Appl. Mater. Interfaces 2011, 3, 918.

[2] E. Audet, F. Mighri, D. Rodrigue, A. Ajji, Cell. Polym. 2018, 37, 103.

[3] P. Gong, G. Wang, M.P. Tran, P. Buahom, S. Zhai, G. Li, C. B. Park, Carbon 2017, 120, 1

[4] M. A. Rodriguez-Perez, Adv. Polym. Sci. 2005, 184, 97.

[5] L. J. Gibson, M. Ashby, Cellular Solids: Structure and Properties, Cambridge University Press, Cambridge 1997.

[6] D. Eaves, Handbook of Polymer Foams, Rapra Technology, Shrewsbury, UK 2004.

[7] M. A. Meyers, J. McKittrick, P.-Y. Chen, Science 2013, 339, 773.

[8] N. Gupta, Mater. Lett. 2007, 61, 979.

[9] L. Cui, S. Kiernan, M. D. Gilchrist, Mater. Sci. Eng., A 2009, 507, 215.

[10] C. V. Vo, F. Bunge, J. Duffy, L. Hood, Cell. Polym. 2011, 30, 137.

[11] L. Monnereau, L. Urbanczyk, J. M. Thomassin, T. Pardoen, C. Bailly, I. Huynen, C. Jérôme, C. Detrembleur, Polymer 2015, 59, 117.

[12] J. Pinto, D. Morselli, V. Bernardo, B. Notario, D. Fragouli, M. A. Rodriguez-Perez, A. Athanassiou, Polymer 2017, 124, 176.

[13] J. Yu, L. Song, F. Chen, P. Fan, L. Sun, M. Zhong, J. Yang, Mater. Today Commun. 2016, 9, 1.

[14] M. T. Ngo, J. S. Dickmann, J. C. Hassler, E. Kiran, J. Supercrit. Fluid. 2016, 109, 1.

[15] C. Zhou, P. Wang, W. Li, Composites, Part B 2011, 42, 318.

[16] M. Trofa, E. Di Maio, P. L. Maffettone, Chem. Eng. J. 2019, 362, 812.

[17] B. Notario, J. Pinto, E. Solorzano, J. A. de Saja, M. Dumon, M. A. Rodriguez-Perez, Polymer. 2015, 56, 57.

[18] L. Grassberger, K. Koch, R. Oberhoffer, A. Müller, H. F. M. Klemmer, R. Strey, Colloid Polym. Sci. 2017, 295, 379.

[19] G. Wang, J. Zhao, L. H. Mark, G. Wang, K. Yu, C. Wang, C. B. Park, G. Zhao, Chem. Eng. J. 2017, 325, 632.

[20] Z. Li, C. Zhu, X. Zhao, Int. J. Heat Mass Transfer 2017, 108, 1982.

[21] D. Miller, V. Kumar, Polymer 2011, 52, 2910.
[22] B. Notario, J. Pinto, M. A. Rodríguez-Perez, Polymer 2015, 63, 116.

[23] J. Martín-de León, J. L. Pura, V. Bernardo, M. Á. Rodríguez-Pérez, Polymer 2019, 170, 16.

[24] S. Perez-Tamarit, B. Notario, E. Solorzano, M. A. Rodriguez-Perez, Mater. Lett. 2018, 210, 39.

[25] J. Pinto, B. Notario, R. Verdejo, M. Dumon, S. Costeux, M. A. Rodriguezperez, Polymer 2017, 113, 27.

[26] B. Notario, J. Pinto, R. Verdejo, M.A. Rodríguez-Pérez, Polymer 2016, 107, 302

[27] B. Notario, A. Ballesteros, J. Pinto, M. A. Rodriguez-Perez, Mater Lett. 2016, 168, 76 .

[28] J. Martin de-Leon, V. Bernardo, M. A. Rodriguez-Perez, Polymers 2016, 8, 265.

[29] S. Costeux, I. Khan, S. P. Bunker, H. K. Jeon, J. Cell. Plast. 2015, 51, 197.

[30] H. Guo, A. Nicolae, V. Kumar, Polymer 2015, 70, 231.

[31] S. Liu, B. Zoetebier, L. Hulsman, Y. Zhang, J. Duvigneau, G. J. Vancso, Polymer (Guildf) 2016, 104.

[32] S. Costeux, L. Zhu, Polymer 2013, 54, 2785.

[33] J. Pinto, M. Dumon, M. A. Rodriguez-Perez, R. Garcia, C. Dietz, J. Phys. Chem. C 2014, 118, 4656.

[34] J. Pinto, J. A. Reglero-Ruiz, M. Dumon, M. A. Rodriguez-Perez, J. Supercrit. Fluid. 2014, 94, 198.

[35] J. Pinto, M. Dumon, M. Pedros, J. Reglero, M. A. Rodriguez-Perez, Chem. Eng. J. 2014, 243, 428.

[36] C. Forest, P. Chaumont, P. Cassagnau, B. Swoboda, P. Sonntag, Polymer 2015, 58, 76

[37] V. Bernardo, J. Martin-de Leon, J. Pinto, T. Catelani, A. Athanassiou, M. A. Rodriguez-Perez, Polymer 2019, 163, 115.

[38] V. Kumar, N. P. Suh, Polym. Eng. Sci. 1990, 30, 1323.

[39] H. Guo, V. Kumar, Polymer 2015, 57, 157.

[40] J. Pinto, E. Solorzano, M. a. Rodriguez-Perez, J. a. de Saja, J. Cell. Plast. 2013, 49, 555 .

[41] V. Kumar, Process Synthesis for Manufacturing Microcellular Thermoplastic Parts, Massachusetts Institute of Technology, Cambridge, MA 1988.

[42] V. Bernardo, J. Martin-de León, E. Laguna-Gutiérrez, M. Á. RodríguezPérez, Eur. Polym. J. 2017, 96, 10.

[43] S. K. Goel, E. J. Beckman, Polym. Eng. Sci. 1994, 34, 1137.

[44] I. Khan, D. Adrian, S. Costeux, Chem. Eng. Sci. 2015, 138, 634.

[45] M. a. Shafi, J. G. Lee, R. W. Flumerfelt, Polym. Eng. Sci. 1996, 36, 1950.

[46] N. H. Fletcher, J. Chem. Phys. 1958, 29, 572. 